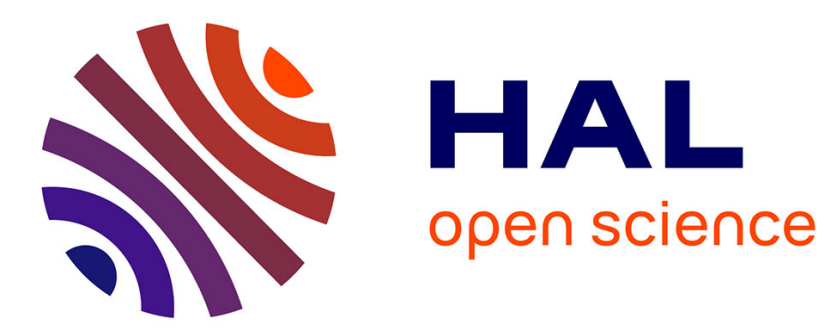

\title{
Improved evidence for the existence of an intermediate phase during hydration of tricalcium silicate
}

\author{
Frank Bellmann, Denis Damidot, Bernd Moeser, Jorgen Skibsted
}

\section{To cite this version:}

Frank Bellmann, Denis Damidot, Bernd Moeser, Jorgen Skibsted. Improved evidence for the existence of an intermediate phase during hydration of tricalcium silicate. Cement and Concrete Research, 2010, 40 (6), pp.875-884. 10.1016/j.cemconres.2010.02.007 . hal-03185717

\section{HAL Id: hal-03185717 \\ https://hal.science/hal-03185717}

Submitted on 8 Jun 2021

HAL is a multi-disciplinary open access archive for the deposit and dissemination of scientific research documents, whether they are published or not. The documents may come from teaching and research institutions in France or abroad, or from public or private research centers.
L'archive ouverte pluridisciplinaire HAL, est destinée au dépôt et à la diffusion de documents scientifiques de niveau recherche, publiés ou non, émanant des établissements d'enseignement et de recherche français ou étrangers, des laboratoires publics ou privés. 


\title{
Improved evidence for the existence of an intermediate phase during hydration of tricalcium silicate
}

\author{
Frank Bellmann ${ }^{\mathrm{a}, *}$, Denis Damidot ${ }^{\mathrm{b}}$, Bernd Möser ${ }^{\mathrm{a}}$, Jørgen Skibsted ${ }^{\mathrm{c}}$ \\ a Institute for Building Materials Science, Bauhaus University Weimar, 99423 Weimar, Germany \\ ${ }^{\mathrm{b}}$ Ecole des Mines de Douai, Civil and Environmental Engineering Department, 941 rue Charles Bourseul, BP 10838, 59508 Doua cedexi, France \\ ' Instrument Center for Solid-State NMR Spectroscopy and Interdisciplinary Nanoscience Center (iNANO), Department of Chemistry, Aarhus University DK-8000 Aarhus C, Denmark
}

\begin{abstract}
Tricalcium silicate $\left(\mathrm{Ca}_{3} \mathrm{SiO}_{5}\right)$ with a very small particle size of approximately $50 \mathrm{~nm}$ has been prepared and hydrated for a very short time ( $5 \mathrm{~min}$ ) by two different modes in a paste experiment, using a water/solidratio of 1.20 , and by hydration as a suspension employing a water/solid-ratio of 4000 . A phase containing uncondensed silicate monomers close to hydrogen atoms (either hydroxyl groups or water molecules) was formed in both experiments. This phase is distinct from anhydrous tricalcium silicate and from the calciumsilicate-hydrate ( $\mathrm{C}-\mathrm{S}-\mathrm{H})$ phase, commonly identified as the hydration product of tricalcium silicate. In the paste experiment, approximately $79 \%$ of silicon atoms were present in the hydrated phase containing silicate monomers as determined from ${ }^{29} \mathrm{Si}\left\{{ }^{1} \mathrm{H}\right\} \mathrm{CP} / \mathrm{MAS}$ NMR. This result is used to show that the hydrated silicate monomers are part of a separate phase and that they cannot be attributed to a hydroxylated surface of tricalcium silicate after contact with water. The phase containing hydrated silicate monomers is metastable with respect to the $\mathrm{C}-\mathrm{S}-\mathrm{H}$ phase since it transforms into the latter in a half saturated calcium hydroxide solution. These data is used to emphasize that the hydration of tricalcium silicate proceeds in two consecutive steps. In the first reaction, an intermediate phase containing hydrated silicate monomers is formed which is subsequently transformed into $\mathrm{C}-\mathrm{S}-\mathrm{H}$ as the final hydration product in the second step. The introduction of an intermediate phase in calculations of the early hydration of tricalcium silicate can explain the presence of the induction period. It is shown that heterogeneous nucleation on appropriate crystal surfaces is able to reduce the length of the induction period and thus to accelerate the reaction of tricalcium silicate with water.
\end{abstract}

\section{Introduction}

Tricalcium silicate $\left(\mathrm{Ca}_{3} \mathrm{SiO}_{5}\right)$ is an inorganic substance that has been found in nature. Modified in composition and crystal structure by ionic substitution and rapid cooling it is called alite, the main constituent of modern Portland cement clinker. It reacts with water at room temperature and forms calcium hydroxide and a semicrystalline calcium silicate hydrate phase denoted C-S-H (Eq. (1)). The composition and structure of the $\mathrm{C}-\mathrm{S}-\mathrm{H}$ phase are variable and thus not perfectly established. In contact with a saturated Portlandite $\left(\mathrm{Ca}(\mathrm{OH})_{2}\right)$ solution, it is supposed to have an atomic calcium/siliconratio of approximately 1.7 , a water content of $20-44 \%$, more or less long chains (dreierketten) of silicate tetrahedra, and structural similarities to a calcium silicate hydrate mineral (tobermorite) [1]. More than twenty crystalline calcium silicate hydrates are known to exist, however, in this paper the term $\mathrm{C}-\mathrm{S}-\mathrm{H}$ is reserved to the final

\footnotetext{
* Corresponding author.

E-mail address: frank.bellmann@uni-weimar.de (F. Bellmann).
}

product resulting from tricalcium silicate hydration at ambient temperature.

$\mathrm{Ca}_{3} \mathrm{SiO}_{5}+(1.3+\mathrm{x}) \mathrm{H}_{2} \mathrm{O} \rightarrow 1.7 \mathrm{CaO} \cdot \mathrm{SiO}_{2} \cdot \mathrm{xH}_{2} \mathrm{O}+1.3 \mathrm{Ca}(\mathrm{OH})_{2}$

Thermodynamic calculations on the reaction of tricalcium silicate with water forming $\mathrm{C}-\mathrm{S}-\mathrm{H}$ and calcium hydroxide have been carried out [2,3, Appendix A]. These calculations predict that the solubility of $\mathrm{Ca}_{3} \mathrm{SiO}_{5}$ in water is much higher than the solubility of the reaction products. Beside the high solubility of tricalcium silicate, the average dissolution rate of $\mathrm{Ca}_{3} \mathrm{SiO}_{5}$ is close to $10 \mu \mathrm{mol} /\left(\mathrm{s} \mathrm{m}^{2}\right)$ in pure water and decreases to less than $0.1 \mu \mathrm{mol} /\left(\mathrm{s} \mathrm{m}^{2}\right)$ in a saturated Portlandite solution [4] and even higher rates have been reported in diluted systems [5]. These rates are very fast and supersaturation with respect to $\mathrm{C}-\mathrm{S}-\mathrm{H}$ is expected to be rapidly reached, allowing a homogeneous formation of nuclei of the hydration products directly from the solution. Calculations referring to the conditions commonly used during reaction of $\mathrm{Ca}_{3} \mathrm{SiO}_{5}$ with water (water/solid-ratio $=0.50$, temperature $=25^{\circ} \mathrm{C}$, specific surface area $=3000 \mathrm{~cm}^{2} / \mathrm{g}$, presence of minor amounts of free lime) show that the dissolution of tricalcium 
silicate proceeds at a very high velocity. Furthermore, they indicate that the formation of the first nuclei of $\mathrm{C}-\mathrm{S}-\mathrm{H}$ can be expected within less than one second after mixing with water. After the formation of these nuclei, there should be a very fast growth of the once formed nuclei in combination with a rapid dissolution of $\mathrm{Ca}_{3} \mathrm{SiO}_{5}$. Such a fast reaction is due to the high difference in Gibbs free energy $(-84.4 \mathrm{~kJ} / \mathrm{mol})$ between the initial $\left(\mathrm{Ca}_{3} \mathrm{SiO}_{5}, \mathrm{H}_{2} \mathrm{O}\right)$ and final $(\mathrm{C}-\mathrm{S}-\mathrm{H}$, $\mathrm{Ca}(\mathrm{OH})_{2}$ ) state of the reaction in combination with a high dissolution rate of tricalcium silicate. Kinetic calculations assuming the aforementioned conditions reveal that the reaction should be completed within a few hours.

It can be concluded that thermodynamic and kinetic calculations indicate that the reaction of $\mathrm{Ca}_{3} \mathrm{SiO}_{5}$ with water to form $\mathrm{C}-\mathrm{S}-\mathrm{H}$ and calcium hydroxide should start directly after contact of this mineral with water and proceed immediately in one kinetic step as observed for the hydration of tricalcium aluminate. In contrast to these predictions, a time lapse denoted as dormant or induction period is observed before the reaction starts to accelerate (Fig. 1). After releasing minor amounts of heat for a short period of time, often attributed to wetting and dissolution, no significant adsorption or liberation of heat is observed for some hours. Acceleration of the reaction starts after about 2-6 h when the main hydration period begins.

The discrepancy between predicted and observed behavior for the $\mathrm{Ca}_{3} \mathrm{SiO}_{5}$ hydration has been discussed for a long time and a few hypotheses have been put forward to explain the experimental results. A review of these ideas considering studies until 1997 was given by Taylor [1] and it was concluded that in the first seconds of hydration, a phase distinct from $\mathrm{C}-\mathrm{S}-\mathrm{H}$ forms on the surface of tricalcium silicate thereby preventing its continued dissolution. The solubility of this first hydrate (termed product B by Taylor based on a designation by Jennings [12]) controls the ionic concentrations in the aqueous phase and generates a slight supersaturation with respect to $\mathrm{C}-\mathrm{S}-\mathrm{H}$ as the final product. The first hydrate is structurally distinct from the $\mathrm{C}-\mathrm{S}-\mathrm{H}$ phase since it contains only monomeric silicate tetrahedra ( $\mathrm{Q}^{\mathrm{O}}$ units) whereas the $\mathrm{SiO}_{4}$ tetrahedra are condensed to more or less long chains in the $\mathrm{C}-\mathrm{S}-\mathrm{H}$ phase. Because the first hydrate exhibits a solubility higher than that of $\mathrm{C}-\mathrm{S}-\mathrm{H}$, it is metastable with respect to the $\mathrm{C}-\mathrm{S}-\mathrm{H}$ and finally transforms into this phase. Taylor [1] concludes from this data that the reaction of tricalcium silicate with water proceeds in two steps. In the first step, $\mathrm{Ca}_{3} \mathrm{SiO}_{5}$ reacts with water and forms an intermediate phase which is converted in the second step into $\mathrm{C}-\mathrm{S}-\mathrm{H}$ as the final product. Both reactions proceed simultaneously during the whole time of hydration (Fig. 2).

This peculiarity can be explained by the comparatively slow condensation/oligomerization of silicate tetrahedra. Tricalcium silicate includes only isolated $\mathrm{SiO}_{4}$ tetrahedra ( $Q^{0}$ sites) and thus, monomeric silicate ions are formed during the fast dissolution of this phase. As discussed before, the dissolution proceeds at such a high

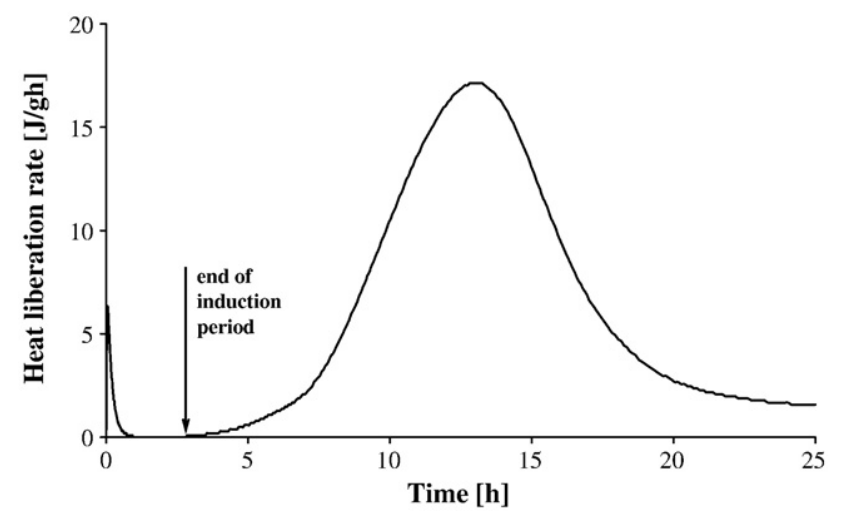

Fig. 1. Heat liberation during hydration of a conventional sample of tricalcium silicate measured by isothermal heat conduction calorimetry $\left(4265 \mathrm{~cm}^{2} / \mathrm{g}, 25^{\circ} \mathrm{C}, w / \mathrm{s}=0.50\right)$.

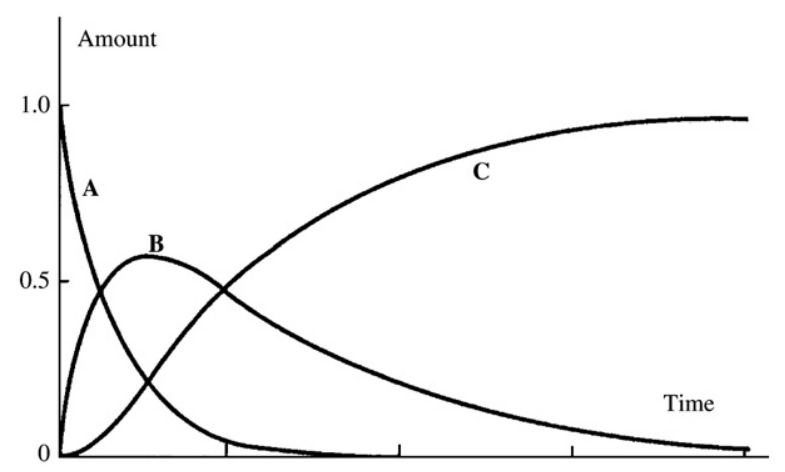

Fig. 2. Schematic representation of a process consisting of two consecutive reactions. Application of this model to the hydration of tricalcium silicate implies that $\mathrm{A}=\mathrm{Ca}_{3} \mathrm{SiO}_{5}, \mathrm{~B}=$ the intermediate phase, and $\mathrm{C}=\mathrm{C}-\mathrm{S}-\mathrm{H}$.

velocity that a supersaturation, allowing a homogeneous nucleation of $\mathrm{C}-\mathrm{S}-\mathrm{H}$, is reached within less than one second. Despite the supersaturation should allow precipitation, C-S-H cannot form in such a short period of time (less than $1 \mathrm{~s}$ ). Formation of $\mathrm{C}-\mathrm{S}-\mathrm{H}$ requires the condensation of silicate tetrahedra forming dimers or longer chains. Since these condensed units are complicated to form, the precipitation of $\mathrm{C}-\mathrm{S}-\mathrm{H}$ nuclei cannot take place instantly and tricalcium silicate continues to dissolve very fast. Within a fraction of a second, concentrations of $\mathrm{Ca}^{2+}$ and $\mathrm{H}_{3} \mathrm{SiO}_{4}^{-}$ions are reached in the aqueous phase that allow nucleation of a calcium silicate hydrate containing only monomeric silicate species and which can be related to the product B defined by Taylor [1]. This phase is assumed to form directly on the surface of tricalcium silicate [1], its precipitation causing a reduction of the silicon concentration in the aqueous phase within the first seconds or minutes $[2,10,11]$. To summarize, the hydration of tricalcium silicate obeys directly Ostwald's rule of stages. The very fast dissolution of tricalcium silicate is responsible for the formation of a phase containing silicate monomers only. This initial reaction is very rapid, but the process continues much more slowly after the first precipitation of hydrates. The reduction of the rate of reaction indicates that the intermediate phase forms a kind of protective layer around the anhydrous core of the particles [1]. After formation of the intermediate phase (product B), the ionic concentrations in the solution are controlled by the solubility of this phase.

A number of spectroscopic results is available that supports the presence of an intermediate phase (product $\mathrm{B}$ ) that is responsible for the isolation of anhydrous cores of $\mathrm{Ca}_{3} \mathrm{SiO}_{5}$ particles from the solution [6-9]. Most important is the paper by Rodger et al. employing ${ }^{29} \mathrm{Si}$ magic-angle spinning (MAS) and ${ }^{29} \mathrm{Si}\left\{{ }^{1} \mathrm{H}\right\}$ cross-polarization $\mathrm{CP} / \mathrm{MAS}$ nuclear magnetic resonance (NMR) spectroscopy [6]. In that study it was shown that resonances from the $\mathrm{C}-\mathrm{S}-\mathrm{H}$, originating from condensed silicate tetrahedra in $\mathrm{Q}^{1}$ (end members in chains) and $\mathrm{Q}^{2}$ (middle groups in chains) $\mathrm{SiO}_{4}$ units, are not observed before the end of the induction period. Instead, minor amounts of hydrated monomeric silicate tetrahedra $\left(Q^{0}\right)$ were detected during the induction period.

Other hypothesis than the protective layer theory have been proposed to explain the existence of an induction period. The reduction of the dissolution rate after the initial reaction in the first minutes has been attributed to the presence of calcium hydroxide or absence of crystallographic defect sites but is in contrast with experimental data. Reported dissolution rates [4,5] are high, even in the aforementioned conditions and will unavoidably lead to ionic concentrations much beyond those observed during hydration of tricalcium silicate [12]. Therefore, the lack of other explanations for the presence of an induction period during $\mathrm{Ca}_{3} \mathrm{SiO}_{5}$ hydration leads to the conclusion that product $\mathrm{B}$ acts as a protective layer around the anhydrous particle cores. However, there is no direct experimental evidence to prove this conclusion. 
Until now, the question of the existence of an intermediate phase, despite its importance for understanding the reaction of Portland cement clinker with water, is not well resolved. For this reason, we focus on this issue in the present paper. The principal aim of this investigation is to complement the results reported by Rodger et al. [6] and Damidot et al. [13] by synthesizing samples containing a high amount of the intermediate phase. Such samples would allow a better characterization of the intermediate phase which was detected only in minor amounts in the previous studies (i.e., $2 \%$ in ref. [6]). An important tool in the present characterization is ${ }^{29} \mathrm{Si}$ MAS NMR employing ${ }^{1} \mathrm{H}$ cross-polarization which allows selective observation of silicate species with hydrogen atoms in their near vicinity. Furthermore, the ${ }^{29}$ Si NMR resonances observed for the intermediate phase are compared with signals reported for crystalline phases in the $\mathrm{CaO}-\mathrm{SiO}_{2}-\mathrm{H}_{2} \mathrm{O}$ system in order to identify structural similarities between the intermediate phase and the crystalline phases if such relations exist. To obtain a high amount of the intermediate phase, the starting material had a very small particle size, which is essential since the surface layer is very thin. If coarse particles are used, the fraction of intermediate phase relative to unreacted $\mathrm{Ca}_{3} \mathrm{SiO}_{5}$ is so low, that the intermediate phase, if existing, can hardly be detected. With progressively lower particle sizes, the amount of intermediate phase relative to unreacted $\mathrm{Ca}_{3} \mathrm{SiO}_{5}$ increases, favoring the detection of this phase.

\section{Experimental}

\subsection{Materials and sample preparation}

$\mathrm{Ca}_{3} \mathrm{SiO}_{5}$ was prepared by high-temperature solid-state reaction between calcium carbonate and amorphous silicon dioxide. The starting materials were mixed in the stoichiometric ratio for tricalcium silicate and then fired in a platinum crucible at $1520^{\circ} \mathrm{C}$. The procedure was repeated twice at a temperature of $1550{ }^{\circ} \mathrm{C}$ to obtain a free lime content of $0.4 \mathrm{wt} . \%$. The synthesized material was ground in a special milling device (MiniCer, Netzsch) aimed to obtain grain sizes in the range of $30-80 \mathrm{~nm}$. Isopropanol was used as a dispersing agent to reduce agglomeration and the sample was dried at $40{ }^{\circ} \mathrm{C}$ after grinding. Remains of isopropanol were removed by heating the powder to $300{ }^{\circ} \mathrm{C}$ for $2 \mathrm{~h}$. The use of the special milling device allowed the obtainment of a very fine powder. However, it was not possible to measure the grain size distribution by common methods such as laser diffraction because the small particles tend to form agglomerates. The particle size was estimated by high-resolution scanning electron microscopy (SEM). Since only a small amount of particles can be analyzed in this way, only a rough estimate of the particle size can be given. The mean particle size obtained by this method was in the range of 40 to $200 \mathrm{~nm}$. For illustration, a micrograph showing typical grains of $\mathrm{Ca}_{3} \mathrm{SiO}_{5}$ is given in Fig. 3. However, the nature of the attractive forces between adjacent grains remains unknown. Also it is likely that small defects are present within the particles that cannot be resolved by SEM. The specific surface area of the powder was measured by $\mathrm{N}_{2}$-adsorption to $21.8 \mathrm{~m}^{2} / \mathrm{g}$. An estimation of the particle size using this value, and assuming a uniform size of all particles and a spherical shape, yields a theoretical mean particle radius of $44 \mathrm{~nm}$.

The obtained tricalcium silicate was hydrated in two different ways. In the first experiment, tricalcium silicate was hydrated under paste conditions while the second hydration was performed as a suspension experiment. The sample referring to the conditions in pastes was prepared using a water/solid-ratio of 1.20 . It was not possible to reduce this value further because the high specific surface of the starting material results in a high water demand to obtain a workable paste. After $5 \mathrm{~min}$ of hydration, the reaction was terminated by drying the paste on a preheated steel plate at $35^{\circ} \mathrm{C}$. By this



Fig. 3. High-resolution SEM micrograph of anhydrous tricalcium silicate ground to particle sizes between 40 and $200 \mathrm{~nm}$.

procedure water is removed within a few seconds from the very thin sample film, thus preventing its carbonation.

The suspension experiment employed a high water/solid-ratio (4000). Calcium and silicate ions are released during dissolution of $\mathrm{Ca}_{3} \mathrm{SiO}_{5}$ and are accumulated in solution. The ionic concentrations rise until spontaneous precipitation takes place. This precipitation is accompanied by the aforementioned decrease in ionic concentration which is especially marked for silicon. A decrease from approximately $[\mathrm{Si}]=1.7 \mathrm{mmol} / \mathrm{l}$ to approximately $[\mathrm{Si}]=1.0 \mathrm{mmol} / \mathrm{l}$ has been reported and attributed to the formation of the first nuclei of ordinary $\mathrm{C}-\mathrm{S}-\mathrm{H}$ [14]. The higher the water/solid-ratio is in the experiment, the higher is the ratio of precipitated silicon to undissolved $\mathrm{Ca}_{3} \mathrm{SiO}_{5}$. $125 \mathrm{mg}$ of nano- $\mathrm{Ca}_{3} \mathrm{SiO}_{5}$ was stirred in $500 \mathrm{~g}$ twice deionised water. All preparations were carried out in a glove box under a nitrogen atmosphere. Water was boiled for $30 \mathrm{~min}$ to expel carbon dioxide before transferring it into the glove box. Mixing was carried out by a high-speed mixer. After $2.5 \mathrm{~min}$, the solution was filtered by a vacuum filtration unit inside the glove box using filter paper with a pore size of $450 \mathrm{~nm}$. Immediately after filtration the solid residue was dried on a preheated steel plate at $35{ }^{\circ} \mathrm{C}$ outside the glove box to evaporate remaining free water within a few seconds. The complete experiment takes less than $10 \mathrm{~min}$ and approximately $12 \mathrm{mg}$ of material are obtained. Considering this small amount of sample, the experiment had to be repeated approximately 50 times to produce the amount of material required for further analysis. After the analysis of the this sample by SEM, XRD and NMR, it was hydrated a second time for $5 \mathrm{~h}$ in the glove box using a water/solid-ratio of 100 and a $50 \%$ calcium hydroxide solution $(\mathrm{Ca}=12.05 \mathrm{mmol} / \mathrm{l}, \mathrm{pH}=12.37)$. Thereby, it was possible to convert the intermediate phase into the final product of hydration (C-S-H). In summary, four samples have been analyzed by XRD, SEM, ${ }^{29} \mathrm{Si}$ MAS NMR, ${ }^{29} \mathrm{Si}\left\{{ }^{1} \mathrm{H}\right\}$ CP MAS NMR, as well as thermal and chemical methods:

1. nano- $\mathrm{Ca}_{3} \mathrm{SiO}_{5}$

2. nano- $\mathrm{Ca}_{3} \mathrm{SiO}_{5}$ hydrated for $5 \mathrm{~min}$ at water/solid-ratio of 1.20

3. nano- $\mathrm{Ca}_{3} \mathrm{SiO}_{5}$ hydrated for $5 \mathrm{~min}$ at water/solid-ratio of 4000

4. sample 3 rehydrated for $5 \mathrm{~h}$ in a $50 \%$ calcium hydroxide solution

\section{2. $X R D$}

The powder X-Ray Diffraction (XRD) experiments were carried out using a Siemens D5000 diffractometer operating with copper radiation at $40 \mathrm{kV}$ and $40 \mathrm{~mA}$. Scanning was performed with a step 
width of $0.03^{\circ} 2 \theta$ over an angular range from 6 to $70^{\circ} 2 \theta$ with a counting time of $5 \mathrm{~s}$ per step.

\subsection{Chemical and thermal analysis}

The contents of $\mathrm{SiO}_{2}$ and $\mathrm{CaO}$ in the bulk samples were determined by chemical analysis. $\mathrm{SiO}_{2}$ was measured gravimetrically and $\mathrm{CaO}$ complexometrically. Loss of ignition (LOI) was obtained after heating the samples to $1000{ }^{\circ} \mathrm{C}$. Total organic carbon (TOC) was determined by spectroscopy (IR adsorption by $\mathrm{CO}_{2}$ emitted from the sample). The thermal analysis was carried out employing a SETARAM setsys 1750 device. DSC and TG signals were recorded during heating the samples in air with $10 \mathrm{~K} / \mathrm{min}$ to $1000{ }^{\circ} \mathrm{C}$.

\subsection{NMR spectroscopy}

The ${ }^{29} \mathrm{Si}$ MAS and ${ }^{29} \mathrm{Si}\left\{{ }^{1} \mathrm{H}\right\} \mathrm{CP} / \mathrm{MAS}$ NMR spectra have been recorded on a Varian INOVA-400 spectrometer (9.39 T) employing a home-built CP/MAS NMR probe for $7 \mathrm{~mm}$ o.d. rotors ( $220 \mu \mathrm{l}$ sample volume). A spinning speed of $\nu_{\mathrm{r}}=6.0 \mathrm{kHz}$ was employed in the ${ }^{29} \mathrm{Si}$ MAS experiments whereas the $\mathrm{CP} / \mathrm{MAS}$ spectra used a lower value $\left(\nu_{\mathrm{r}}=3.0 \mathrm{kHz}\right)$ to minimize the averaging of the ${ }^{1} \mathrm{H}^{29} \mathrm{Si}$ dipolar couplings. The ${ }^{29} \mathrm{Si}$ MAS experiments employed a $\sim 45^{\circ}$ excitation pulse and a relaxation delay of $60 \mathrm{~s}$. The ${ }^{29} \mathrm{Si}\left\{{ }^{1} \mathrm{H}\right\} \mathrm{CP} / \mathrm{MAS}$ NMR spectra used a $10 \mathrm{~s}$ relaxation delay and a $\mathrm{CP}$ contact time of $1.0 \mathrm{~ms}$. For one sample the fraction of hydrated monomeric silicate species was determined from the intensities observed in fully-relaxed ${ }^{29} \mathrm{Si}\left\{{ }^{1} \mathrm{H}\right\} \mathrm{CP} /$ MAS and ${ }^{29}$ Si MAS NMR spectra. This approach requires a preknowledge of the $\mathrm{CP}$ gain factor which was determined from an inversion-recovery ${ }^{29} \mathrm{Si}\left\{{ }^{1} \mathrm{H}\right\} \mathrm{CP} / \mathrm{MAS}$ NMR experiment, using the same method as in an earlier quantitative ${ }^{29} \mathrm{Si}\left\{{ }^{1} \mathrm{H}\right\} \mathrm{CP} / \mathrm{MAS}$ NMR study [15]. For the quantitative evaluation, the ${ }^{29} \mathrm{Si}$ MAS spectrum $\left(90^{\circ}\right.$ excitation pulse, $900 \mathrm{~s}$ relaxation delay) and ${ }^{29} \mathrm{Si}\left\{{ }^{1} \mathrm{H}\right\} \mathrm{CP} / \mathrm{MAS}$ spectrum (5.0 ms contact time, 20 s relaxation delay) used the same rf field strengths as the ${ }^{29} \mathrm{Si}\left\{{ }^{1} \mathrm{H}\right\} \mathrm{CP} /$ MAS inversion-recovery experiment $\left(\gamma \mathrm{B}_{1} / 2 \pi=18 \mathrm{kHz}\right.$ for ${ }^{29} \mathrm{Si}, \gamma \mathrm{B}_{2} /$ $2 \pi=21 \mathrm{kHz}$ for ${ }^{1} \mathrm{H}$ during the $\mathrm{CP}$ contact, and $\gamma \mathrm{B}_{2} / 2 \pi=30 \mathrm{kHz}$ for the initial ${ }^{1} \mathrm{H}$ pulse and ${ }^{1} \mathrm{H}$ decoupling during data acquisition).

\subsection{Scanning electron microscopy (SEM)}

The microstructure of all samples in their native state was investigated using a high-resolution Environmental Scanning Electron Microscope with Field Emission Gun (ESEM-FEG) produced by FEI/Philips (XL30). The samples were observed under the following conditions: Temperature $=12{ }^{\circ} \mathrm{C}$, water vapour pressure $=10$ Torr, Gaseous Secondary Electron Detector (GSED), acceleration voltage $=30 \mathrm{kV}$, and beam current $=120 \mathrm{pA}($ spot 3$)$.

\section{Results}

\subsection{Powder XRD measurements}

The results from the XRD examinations are illustrated in Fig. 4. In the anhydrous tricalcium silicate (nano- $\mathrm{Ca}_{3} \mathrm{SiO}_{5}$ ), only the triclinic form of $\mathrm{Ca}_{3} \mathrm{SiO}_{5}$ is identified. However, the peaks are very broad as a result of small crystallite sizes and serious microstrain introduced by grinding [16]. Quantitative phase analysis using the Rietveld method and an anhydrous sample spiked with $20 \%$ zincite $(\mathrm{ZnO})$ as internal standard reveals an amorphous content as high as $41 \%$. In contrast to this, the amorphous content in micrometric $\mathrm{Ca}_{3} \mathrm{SiO}_{5}$ is usually below the limit of detection. No other phases than tricalcium silicate were detected. After hydration for $5 \mathrm{~min}$ at a water/solid-ratio of 1.20 , unreacted tricalcium silicate is still present, again exhibiting peak broadening due to small crystallite sizes and microstrain. In addition, minor amounts of calcite were detected. Anhydrous tricalcium silicate is also identified in the sample hydrated for $5 \mathrm{~min}$ at a high water/solid-ratio $(w / s=4000)$.

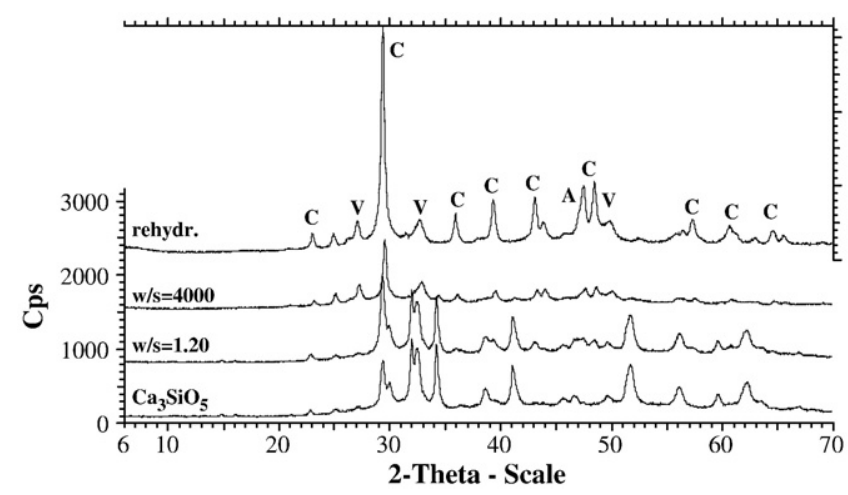

Fig. 4. Results from powder XRD analysis of the four studied samples (C: calcite, $\mathrm{V}$ : vaterite, A: aragonite, the peaks from tricalcium silicate are not labeled).

However, the amount of this phase is much lower than in the sample hydrated at a low water/solid-ratio. The calcium carbonate polymorphs (calcite, vaterite, and aragonite) are detected in this sample. After the second hydration of this sample, no trace of tricalcium silicate is seen by XRD. Only calcite, vaterite and aragonite are found. The presence of broad reflections from the C-S-H phase, usually observed at 29.4, 32.0, and $50.0^{\circ} 2 \theta$ could not be confirmed as a result of peak overlap with reflections from other phases.

\subsection{Chemical analysis}

The results of the chemical analysis are given in Table 1. Apparently, a high loss of ignition is obtained when analyzing the anhydrous tricalcium silicate. This was confirmed by thermal analysis (see below). However, XRD, thermal analysis, and NMR data indicate that calcite is formed during heating the sample. Other silicate phases than $\mathrm{Ca}_{3} \mathrm{SiO}_{5}$ were not be detected by NMR (see below). The anhydrous tricalcium silicate contained $0.4 \mathrm{wt}$.\% organic carbon. After oxidation of this organic carbon, potentially $3.8 \mathrm{wt}$ \% calcium carbonate may be formed ignoring the presence of any inorganic carbon.

\subsection{Thermal analysis}

The thermal analysis of anhydrous tricalcium silicate showed a minor mass loss up to $150{ }^{\circ} \mathrm{C}(0.8 \%)$ followed by a nearly constant mass in the range from $150{ }^{\circ} \mathrm{C}$ to $300{ }^{\circ} \mathrm{C}$. This indicates that water is absorbed from the atmosphere forming a minor amount of hydrates at the surface of tricalcium silicate. The high specific surface of the starting material favors the attraction of water, isopropanol, carbon dioxide or other phases. An increase of temperature results in a broad endothermic peak between $300{ }^{\circ} \mathrm{C}$ and $500{ }^{\circ} \mathrm{C}$ in combination with a mass loss of $2.6 \%$. This is attributed to the reaction of the remaining isopropanol, which was partly evaporated, and partly formed calcium carbonate with dehydrated calcium silicate hydrate [17]. The dissociation of this calcium carbonate takes place between $650{ }^{\circ} \mathrm{C}$ and $750{ }^{\circ} \mathrm{C}$. A mass loss of $5.1 \%$ was recorded in that interval corresponding to $12.6 \%$ calcium carbonate. This data indicates that the

Table 1

Chemical composition of the four studied samples.

\begin{tabular}{|c|c|c|c|}
\hline Sample & LOI $^{\mathrm{a}}$ [wt.\%] & $\mathrm{SiO}_{2}$ [wt.\%] & $\mathrm{CaO}$ [wt.\%] \\
\hline nanoCa $\mathrm{SiO}_{5}$ & 9.6 & 23.8 & 65.2 \\
\hline nanoCa ${ }_{3} \mathrm{SiO}_{5}, 5 \mathrm{~min}$ at $w / s=1.20$ & 21.0 & 21.0 & 57.2 \\
\hline nanoCa ${ }_{3} \mathrm{SiO}_{5}, 5 \mathrm{~min}$ at $w / s=4000$ & 33.1 & 19.9 & 45.3 \\
\hline $\begin{array}{l}\text { nanoCa }_{3} \mathrm{SiO}_{5}, 5 \mathrm{~min} \text { at } \\
\quad w / s=4000+5 \text { h at } w / s=100\end{array}$ & 37.7 & 18.8 & 42.4 \\
\hline
\end{tabular}

a Loss of ignition at $1000^{\circ} \mathrm{C}$ 
high loss of ignition measured for anhydrous tricalcium silicate is only to a minor extent due to the presence of chemisorbed water.

The sample hydrated for 5 minutes at a water/solid-ratio of 1.20 showed a mass loss of $1.4 \%$ upon heating to $200{ }^{\circ} \mathrm{C}$ in combination with an endothermic peak. This is attributed to dehydration of calcium silicate hydrates. Also in this sample, a nearly constant mass was observed ranging from $200{ }^{\circ} \mathrm{C}$ to approximately $350{ }^{\circ} \mathrm{C}$. Surprisingly, there was a loss of mass (3.9\%) almost constantly over the period from $350{ }^{\circ} \mathrm{C}$ to $700{ }^{\circ} \mathrm{C}$ which is not due to the dehydroxylation of calcium hydroxide. It was followed by a sharp endothermic signal $\left(700-850{ }^{\circ} \mathrm{C}\right.$ ), reflecting the dissociation of calcium carbonate. A mass loss of $6.1 \%$ was recorded for the last temperature range, indicating the presence of $13.8 \%$ calcium carbonate. A minor amount of isopropanol may potentially also have been present in this sample. These data are in contrast to the LOI-result (Table 1) that has been confirmed by repeating the analysis under different conditions.

The thermal behavior of the sample hydrated for $5 \mathrm{~min}$ at a much higher water/solid-ratio $(w / s=4000)$ is rather different from what is expected for hydrated tricalcium silicate. There is an almost constant loss of mass $(28 \%)$ between $100{ }^{\circ} \mathrm{C}$ and approximately $700{ }^{\circ} \mathrm{C}$. In addition, a very broad exothermic signal with a peak at about $300{ }^{\circ} \mathrm{C}$ is observed. The dissociation of calcium carbonate results in a mass loss of $3.5 \%$ between $700{ }^{\circ} \mathrm{C}$ and $800{ }^{\circ} \mathrm{C}$ indicating the presence $8.0 \%$ $\mathrm{CaCO}_{3}$. For this sample hydrated for the second time, a similar thermal behavior is observed with a mass loss of $30.7 \%$ between $100{ }^{\circ} \mathrm{C}$ and $700{ }^{\circ} \mathrm{C}$ and a broad exothermic peak at approximately $300{ }^{\circ} \mathrm{C}$. The amount of calcium carbonate (14.8\%) calculated from the mass loss (6.5\%) between 700 and $800{ }^{\circ} \mathrm{C}$ is higher than the quantity in the sample before the second hydration.

\subsection{ESEM}

The samples in this study were very fine powders allowing a direct examination by ESEM without coating. Anhydrous tricalcium silicate showed the presence of agglomerates with diameters between 2 and $10 \mu \mathrm{m}$. The apparent size of the single particles estimated by ESEM (40-200 nm) was significantly smaller (Fig. 3). However, the nature of the contact points between the particles could not be assessed. After hydration for $5 \mathrm{~min}$ under paste conditions (water/solidratio $=1.20$ ), more rounded particle shapes were observed with diameters between 50 and $200 \mathrm{~nm}$ (Fig. 5). Also in this sample, agglomeration of small particles was evident. Under suspension conditions (water/solid-ratio $=4000$ ), the apparent size of the single

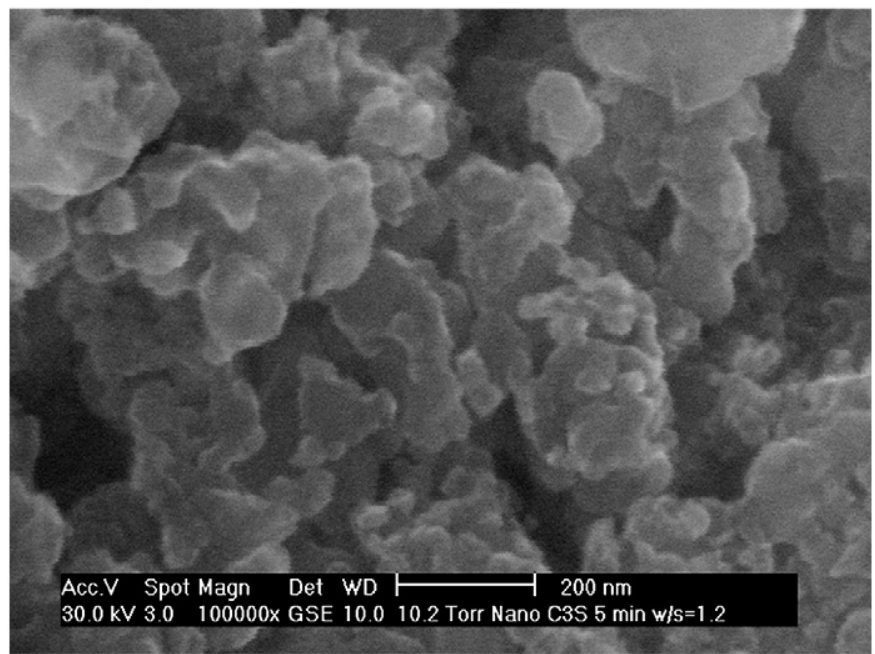

Fig. 5. SEM micrograph of nano- $\mathrm{Ca}_{3} \mathrm{SiO}_{5}$ particles after 5 min hydration under paste conditions.

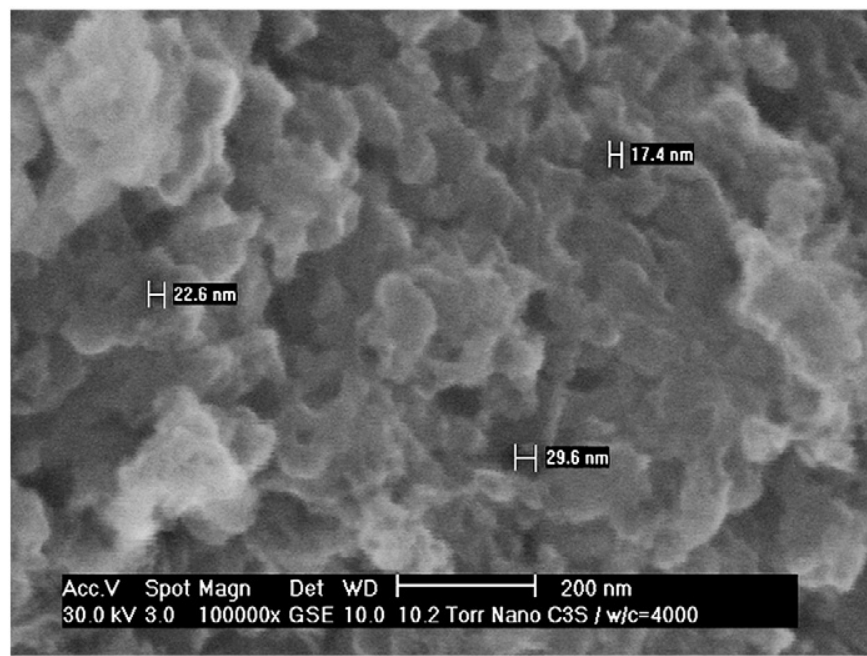

Fig. 6. SEM micrograph of nano- $\mathrm{Ca}_{3} \mathrm{SiO}_{5}$ after 5 min hydration in a suspension.

particles was even smaller (approximately $20-50 \mathrm{~nm}$ ) than the particle size of the anhydrous $\mathrm{Ca}_{3} \mathrm{SiO}_{5}$ (Fig. 6). The hydrates were unstable in the electron beam at high magnifications. These particles are replaced by foil-like $\mathrm{C}-\mathrm{S}-\mathrm{H}$ with a thickness of approximately $5 \mathrm{~nm}$ (Fig. 7) after the second hydration of this sample. Approximately $50 \mathrm{~nm}$ large particles with rounded shapes (not shown in Fig. 7) are observed in addition to $\mathrm{C}-\mathrm{S}-\mathrm{H}$.

\subsection{NMR spectroscopy}

The ${ }^{29} \mathrm{Si}$ MAS NMR spectrum of anhydrous tricalcium silicate (nano- $\mathrm{Ca}_{3} \mathrm{SiO}_{5}$, Fig. 8a) reveals a number of overlapping resonances in the range from $-67 \mathrm{ppm}$ to $-78 \mathrm{ppm}$, reflecting the presence of monomeric $\mathrm{SiO}_{4}$ tetrahedra only in this material. Triclinic $\mathrm{Ca}_{3} \mathrm{SiO}_{5}$ contains 9 distinct Si sites in the asymmetric unit [18] which can be resolved by ${ }^{29} \mathrm{Si}$ MAS NMR for highly crystalline samples of $\mathrm{Ca}_{3} \mathrm{SiO}_{5}$ $[19,20]$. Such spectra include two resonances at high frequency $\left(\delta_{\text {iso }}=-68.93 \mathrm{ppm}\right.$ and $\left.\delta_{\text {iso }}=-69.04 \mathrm{ppm}\right)$ and four resonances in a narrow range from $-73.44 \mathrm{ppm}$ to $-73.84 \mathrm{ppm}$ [19]. These chemical shifts agree well with the distinct peaks at $\delta_{\text {iso }}=-69.2 \mathrm{ppm}$ and $\delta_{\text {iso }}=-73.8 \mathrm{ppm}$, observed in the ${ }^{29} \mathrm{Si}$ MAS NMR spectrum of nano$\mathrm{Ca}_{3} \mathrm{SiO}_{5}$ (Fig. 8a). The lack in resolution of resonances from all of the

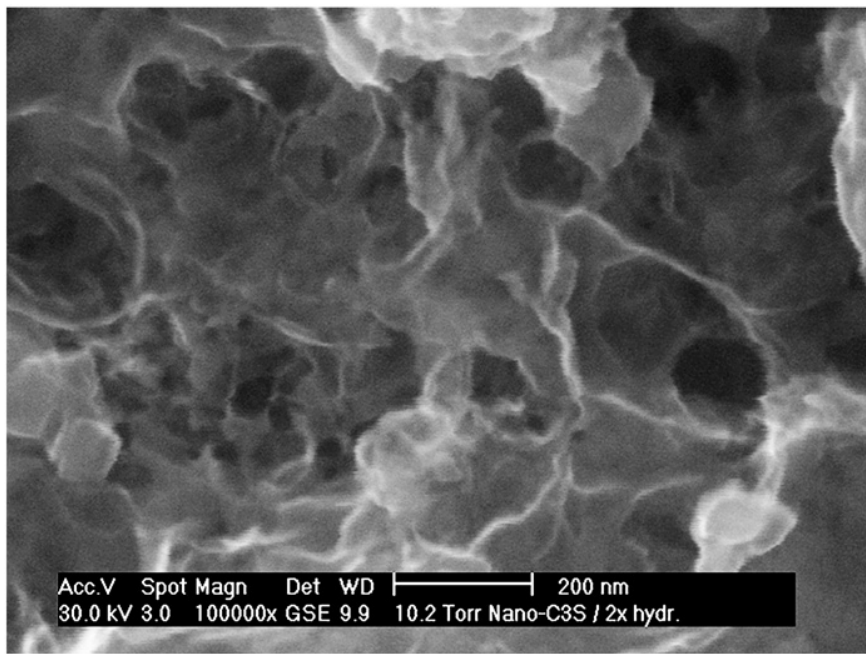

Fig. 7. SEM micrograph of foil-like C-S-H after 5 min hydration at $w / s=4000$ followed by $5 \mathrm{~h}$ of hydration at $w / s=100$ in a $50 \%$ calcium hydroxide solution. 


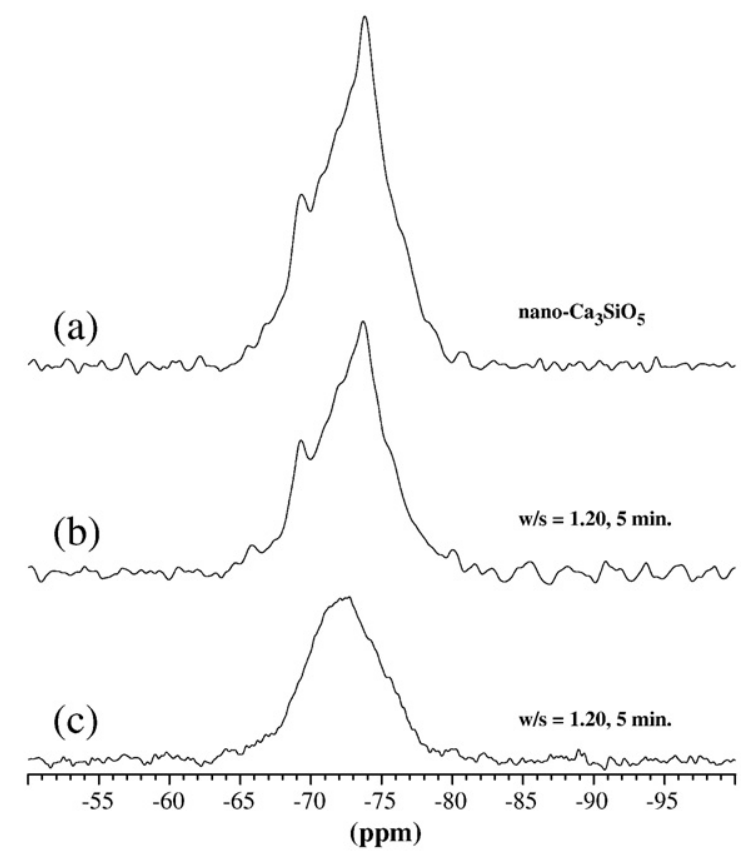

Fig. 8. ${ }^{29} \mathrm{Si}$ MAS NMR spectra of (a) anhydrous tricalcium silicate (1344 scans), (b) tricalcium silicate after hydration for 5 min under paste conditions using a water/ solid-ratio $=1.20$ (1360 scans), and (c) ${ }^{29} \mathrm{Si}\left\{{ }^{1} \mathrm{H}\right\} \mathrm{CP} / \mathrm{MAS}$ NMR spectrum of the hydrated paste sample (2304 scans).

9 Si sites may reflect the small crystallite sizes and microstrains introduced by grinding, which results in a dispersion of the chemical shifts. The absence of resonances at lower frequencies from $\mathrm{Q}^{1}$ and $\mathrm{Q}^{2}$ $\mathrm{SiO}_{4}$ tetrahedra ( $-78 \mathrm{ppm}$ to $-88 \mathrm{ppm}$ ) confirms that the sample does not contain even a small amount of $\mathrm{C}-\mathrm{S}-\mathrm{H}$.

Hydration of nano- $\mathrm{Ca}_{3} \mathrm{SiO}_{5}$ for 5 min under paste conditions (i.e., a water/solid-ratio of 1.20 ) results in a material with a ${ }^{29} \mathrm{Si} \mathrm{MAS} \mathrm{NMR}$ spectrum (Fig. 8b) that is not much different from the spectrum of the anhydrous phase, although minor differences in the relative intensities of the peaks at $\delta_{\text {iso }}=-69.2 \mathrm{ppm}$ and $\delta_{\text {iso }}=-73.8 \mathrm{ppm}$ are observed for the two samples. However, the corresponding ${ }^{29} \mathrm{Si}\left\{{ }^{1} \mathrm{H}\right\}$ CP/MAS NMR spectrum of the paste sample (Fig. 8c) shows a somewhat broadened resonance with a center of gravity at $\delta_{\mathrm{cg}}=-72.6 \mathrm{ppm}$, covering the same spectral range as the resonances in the single-pulse ${ }^{29} \mathrm{Si}$ MAS NMR spectra. This resonance unambiguously demonstrates the presence of hydrated monomers of $\mathrm{SiO}_{4}$ tetrahedra $\left(\mathrm{Q}^{0}\right.$ units) since only ${ }^{29} \mathrm{Si}$ atoms with ${ }^{1} \mathrm{H}$ in their near vicinity are detected by the ${ }^{29} \mathrm{Si}\left\{{ }^{1} \mathrm{H}\right\} \mathrm{CP} / \mathrm{MAS}$ technique. The rather featureless character of the resonance may reflect the presence of a number of different environments for these $Q^{0}$ species and thereby a less-ordered structure on the nanoscale of the hydrated material.

The fraction of Si atoms present in anhydrous tricalcium silicate and in the hydrated phase including silicate monomers were estimated from the intensities in fully-relaxed ${ }^{29} \mathrm{Si}$ MAS and ${ }^{29} \mathrm{Si}\left\{{ }^{1} \mathrm{H}\right\}$ $\mathrm{CP} / \mathrm{MAS}$ spectra, employing the $\mathrm{CP}$ gain factor from an inversionrecovery ${ }^{29} \mathrm{Si}\left\{{ }^{1} \mathrm{H}\right\} \mathrm{CP} / \mathrm{MAS}$ experiment (c.f., Experimental Section 2.4 ). The analysis of the intensities in the inversion-recovery experiment resulted in a $\mathrm{CP}$ gain factor of $G_{\mathrm{CP}}=1.02 \pm 0.10$ and a ${ }^{29} \mathrm{Si}$ spin-lattice relaxation time of $T_{1}=178 \pm 18 \mathrm{~s}$ for the hydrated monomers of $\mathrm{SiO}_{4}$ tetrahedra. This gain factor along with the intensities observed in the ${ }^{29} \mathrm{Si}$ MAS and ${ }^{29} \mathrm{Si}\{\mathrm{H}\} \mathrm{CP} / \mathrm{MAS}$ NMR spectra gives that $79 \pm 6 \%$ of the $\mathrm{Q}^{0} \mathrm{SiO}_{4}$ units in the sample are present as hydrated $\mathrm{SiO}_{4}$ monomers in the hydrated phase in the sample. The remaining $21 \%$ can be attributed to unhydrated tricalcium silicate.

Hydration of nano- $\mathrm{Ca}_{3} \mathrm{SiO}_{5}$ for 5 min under suspension conditions (i.e., a water/solid-ratio of 4000 ) results in a sample with the ${ }^{29} \mathrm{Si}$ MAS
NMR spectrum shown in Fig. 9a, which contains resonances from $Q^{1}, Q^{2}$, and $\mathrm{Q}^{3} \mathrm{SiO}_{4}$ sites in addition to the monomeric species. Quantitative information about the distribution of silicon over these sites is obtained from a deconvolution of the ${ }^{29} \mathrm{Si}$ MAS spectrum, resulting in relative intensities of $28 \%$ for silicon in $\mathrm{Q}^{0}$ sites $\left(\delta_{\text {iso }}=-74 \mathrm{ppm}\right), 27 \%$ in $\mathrm{Q}^{1}$ sites $\left(\delta_{\text {iso }}=-80 \mathrm{ppm}\right), 34 \%$ in $\mathrm{Q}^{2}$ sites $\left(\delta_{\text {iso }}=-86 \mathrm{ppm}\right)$, and $11 \%$ in $\mathrm{Q}^{3}$ sites $\left(\delta_{\text {iso }}=-90 \mathrm{ppm}\right)$. Examination of the sample by ${ }^{29} \mathrm{Si}\left\{{ }^{1} \mathrm{H}\right\} \mathrm{CP} / \mathrm{MAS}$ NMR (Fig. 9b) confirms the presence of a hydrate or hydroxylated surface containing silicate monomers by the observed intensity in the range from $-68 \mathrm{ppm}$ to $-76 \mathrm{ppm}$, although the spectrum is dominated by distinct resonances from the $\mathrm{Q}^{1}$ and $\mathrm{Q}^{2}$ sites. A comparison of the $\mathrm{Q}^{0}$ resonances in the ${ }^{29} \mathrm{Si}\left\{{ }^{1} \mathrm{H}\right\} \mathrm{CP} / \mathrm{MAS}$ NMR spectra of the samples prepared under paste (Fig. 8c) and suspension (Fig. 9b) conditions indicates only minor differences in the relative peak intensities. Furthermore, comparison of the intensities in the corresponding single-pulse ${ }^{29} \mathrm{Si}$ MAS NMR spectra clearly reveals that a much smaller amount of the hydrated monomer $\mathrm{SiO}_{4}$ species is present in the suspension sample relative to the paste sample.

The ${ }^{29} \mathrm{Si}$ MAS NMR spectrum of the suspension sample hydrated for a second time (Fig. 10a) shows no intensity in the $Q^{0}$ region of the spectrum and thereby demonstrates a full degree of reaction for tricalcium silicate and a full conversion of the hydrated phase containing monomeric $\mathrm{SiO}_{4}$ sites. Only resonances from $\mathrm{Q}^{1}, \mathrm{Q}^{2}$, and a small fraction of $\mathrm{Q}^{3} \mathrm{SiO}_{4}$ tetrahedra are observed with an appearance that is quite typical for synthetic C-S-H samples. Deconvolution of the spectrum gives relative intensities of $39 \%$ for the $\mathrm{Q}^{1}\left(\delta_{\text {iso }}=-80 \mathrm{ppm}\right)$ sites, $53 \%$ for $\mathrm{Q}^{2}\left(\delta_{\text {iso }}=-86 \mathrm{ppm}\right)$, and $8 \%$ for the $\mathrm{Q}^{3}\left(\delta_{\text {iso }}=\right.$ $-90 \mathrm{ppm}) \mathrm{SiO}_{4}$ tetrahedra. The same resonances are also observed in the ${ }^{29} \mathrm{Si}\left\{{ }^{1} \mathrm{H}\right\}$ CP MAS NMR spectrum (Fig. 10b), however, with different relative intensities reflecting a difference in $\mathrm{CP}$ efficiency (i.e., internuclear Si-H distances) for the $\mathrm{Q}^{1}, \mathrm{Q}^{2}$, and $\mathrm{Q}^{3}$ sites.

\section{Discussion}

Nanosized tricalcium silicate was produced for this study with particle diameters between 40 and $200 \mathrm{~nm}$. The specific surface measured by nitrogen absorption was approximately $22 \mathrm{~m}^{2} / \mathrm{g}$. An estimation of the mean particle diameter from the specific surface results in a value of $88 \mathrm{~nm}$ if a spherical shape and a uniform particle size are assumed. The existence of nano-cracks cannot be excluded. It can be assumed that the surface accessible to water has been exactly

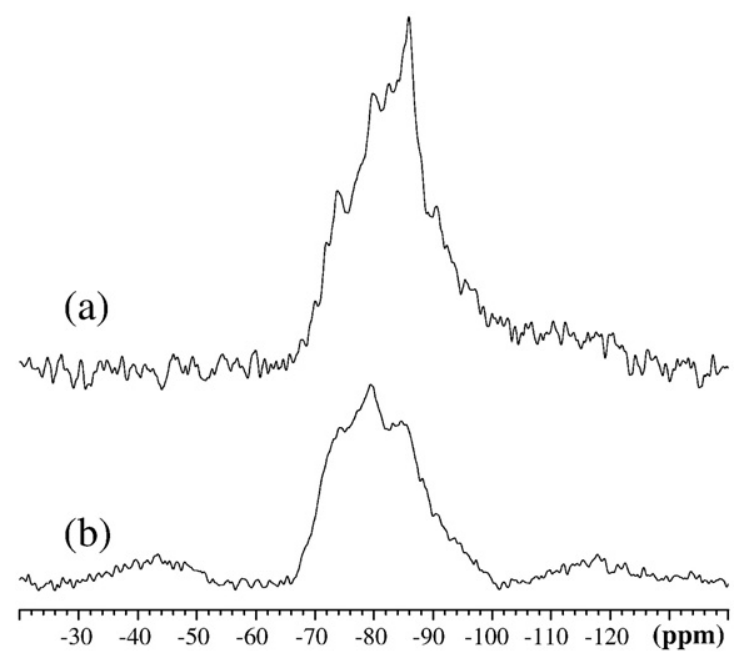

Fig. 9. (a) ${ }^{29} \mathrm{Si}$ MAS NMR spectrum (3129 scans) and (b) ${ }^{29} \mathrm{Si}\left\{{ }^{1} \mathrm{H}\right\}$ CP/MAS NMR spectrum $(14,628$ scans) of tricalcium silicate after hydration in a suspension (water/ solid-ratio $=4000,5 \mathrm{~min}$ ). First-order spinning sidebands are observed in part (b) around -30 to $-50 \mathrm{ppm}$ and -105 to $-125 \mathrm{ppm}$. 


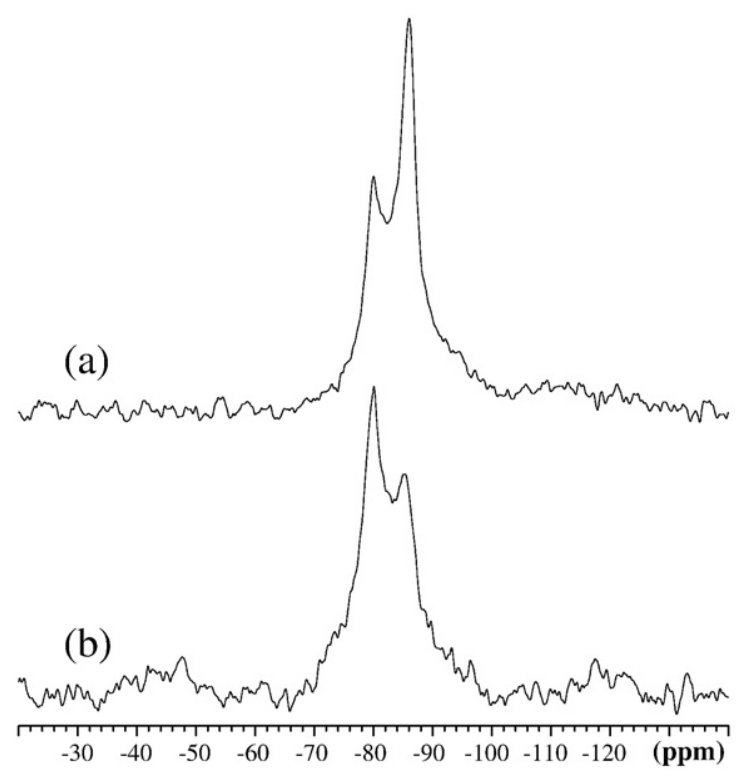

Fig. 10. (a) ${ }^{29} \mathrm{Si}$ MAS NMR spectrum (2048 scans) and (b) ${ }^{29} \mathrm{Si}\left\{{ }^{1} \mathrm{H}\right\} \mathrm{CP} / \mathrm{MAS}$ NMR spectrum (17,152 scans) of tricalcium silicate after two times of hydration (5 min at a water/solid-ratio $=4000$ and later on $5 \mathrm{~h}$ at a water/solid-ratio $=100$ ). Low-intensity first-order spinning sidebands may be identified in part (b) around -35 to $-50 \mathrm{ppm}$ and -110 to $-125 \mathrm{ppm}$.

determined by nitrogen adsorption since the size of water and nitrogen molecules is in the same range. Grinding has led to partial amorphization, serious microstrain and reduction of crystallite size but NMR data shows that there was no phase transformation. The impact of partial amorphization and high surface has only a marginal impact on the change in Gibbs free energy during the hydration process.

Consideration of the high specific surface and the high reactivity explains well that this material is able to absorb water from the atmosphere and thus exhibits slightly different properties than micrometric tricalcium silicate. Minor amounts of hydrates may have formed before initiating the hydration experiments. Thermal analysis indicates further that heating the nano- $\mathrm{Ca}_{3} \mathrm{SiO}_{5}$ sample to a temperature of $300{ }^{\circ} \mathrm{C}$ is not high enough to warrant the evaporation of isoproanol used as a dispersing agent during grinding. The starting material contained $0.4 \mathrm{wt}$.\% organic carbon. Absorption of water has possibly led to the formation of a hydroxylated surface or a hydrate containing $\mathrm{Q}^{0} \mathrm{SiO}_{4}$ units close to hydrogen atoms because no condensation of $\mathrm{SiO}_{4}$ tetrahedra ( $\mathrm{Q}^{1}$ or higher) was observed for the nano- $\mathrm{Ca}_{3} \mathrm{SiO}_{5}$ sample. Due to the action of carbon dioxide and water, a small amount of calcium carbonate has formed in tricalcium silicate before the experiments were initiated. However, ${ }^{29} \mathrm{Si}$ MAS NMR spectroscopy can be used to show that condensed silicate phases such as $\mathrm{C}-\mathrm{S}-\mathrm{H}$ are absent in the anhydrous sample. It can be assumed that the formation of calcium carbonate occurs when heating the sample [17] resulting in a high loss of ignition.

After exposure of $\mathrm{Ca}_{3} \mathrm{SiO}_{5}$ for $5 \mathrm{~min}$ to water at a water/solid-ratio of 1.20 , the formation of a hydroxylated surface or a hydrate containing $\mathrm{Q}^{0}$ units is unambiguously observed by a broadened resonance at $\delta_{\mathrm{cg}}=-72.6 \mathrm{ppm}$ in the ${ }^{29} \mathrm{Si}\left\{{ }^{1} \mathrm{H}\right\} \mathrm{CP} / \mathrm{MAS}$ NMR spectrum. This peak has also been observed in earlier studies by Rodger et al. [5] and Damidot et al. [13]. Due to the high specific surface of the starting material used in our investigation, the proof of the presence of such a resonance is much more convincing in this work as compared to the earlier studies. The monomeric $\mathrm{SiO}_{4}$ tetrahedra close to hydrogen atoms can be bound in a less crystalline hydrate phase (amorphous to $\mathrm{X}$-rays) or in a hydroxylated surface layer. Both theories have been discussed in the literature.
There are several crystalline calcium silicate hydrates known to contain only $\mathrm{Q}^{0}$ units. These include afwillite $\left(\mathrm{Ca}_{3}\left(\mathrm{HSiO}_{4}\right)_{2} \cdot 2 \mathrm{H}_{2} \mathrm{O}\right)$, calciochondrodite $\left(\mathrm{Ca}_{5}\left(\mathrm{SiO}_{4}\right)_{2}(\mathrm{OH})_{2}\right)$, and alpha dicalcium silicate hydrate $\left(\alpha-\mathrm{Ca}_{2}\left(\mathrm{SiO}_{3} \mathrm{OH}\right) \mathrm{OH}\right)$. The isotropic ${ }^{29} \mathrm{Si}$ chemical shifts for these substances are -71.3 and $-73.3 \mathrm{ppm}$ [21], $-72.7 \mathrm{ppm}$ [22], and $-72.7 \mathrm{ppm}$ [23], respectively. These values are in accordance with the chemical shift range observed for the monomeric $\mathrm{SiO}_{4}$ species of the nano- $\mathrm{Ca}_{3} \mathrm{SiO}_{5}$ sample hydrated for $5 \mathrm{~min}$ at $w / \mathrm{s}=1.20$ in this study. However, the resonances observed for the pure crystalline calcium silicate hydrates [21-23] are very narrow when compared to the spectra obtained for nano- $\mathrm{Ca}_{3} \mathrm{SiO}_{5}$ before and after hydration (Fig. 8). The broad and rather featureless shape of the $\mathrm{Q}^{0}$ resonance in the ${ }^{29} \mathrm{Si}\left\{{ }^{1} \mathrm{H}\right\} \mathrm{CP} / \mathrm{MAS}$ NMR spectrum suggests the presence of a range of different environments for the hydrated monomers of $\mathrm{SiO}_{4}$ tetrahedra. It can be attributed to a poorly crystalline phase or a distorted hydroxylated surface. The broadened shape of the resonance implies some variation in the $\mathrm{Si}-\mathrm{O} \cdots \mathrm{H}$ environments and thereby the absence of silicate units in a highly ordered environment. In agreement with this conclusion, no peaks are observed in the XRD analysis of this sample.

A similar resonance is observed in the ${ }^{29} \mathrm{Si}\left\{{ }^{1} \mathrm{H}\right\}$ CP MAS NMR spectrum of the sample hydrated at a much higher water/solid-ratio $(w / s=4000)$ which also shows that $\mathrm{C}-\mathrm{S}-\mathrm{H}$ has precipitated. The formation of $\mathrm{C}-\mathrm{S}-\mathrm{H}$ phase is due to the longer time span before the solution is saturated with respect to the intermediate phase or hydroxylated surface. Subsequently, there is an opportunity to form $\mathrm{C}-\mathrm{S}-\mathrm{H}$ containing dimers or even longer chains by condensation of silicate tetrahedra. It can be concluded that the preparation of the intermediate phase by employing a water/solid-ratio as high as 4000 was less successful than by using a water/solid-ratio of 1.20 . The hydrated sample contains some calcium carbonate, however, of the same order of magnitude as the starting material. Thus, detection of $\mathrm{Q}^{3}$ sites in that sample cannot be explained by serious carbonation. After the second hydration of this sample, the metastable character of the intermediate phase or hydroxylated surface is apparent from the absence of all $Q^{0}$ resonances in the ${ }^{29} \mathrm{Si}$ MAS NMR spectrum. All nano$\mathrm{Ca}_{3} \mathrm{SiO}_{5}$ has been consumed and all of the intermediate phase has transformed into $\mathrm{C}-\mathrm{S}-\mathrm{H}$ as the final hydration product.

The aforementioned data can be used to discuss if the hydrated silicate monomers are present in a hydroxylated surface or in a separate phase, termed product B. A hydroxylated surface of tricalcium silicate implies that the silicate tetrahedra on the surface possess some oxygen ions that are connected to hydrogen. Therefore, the thickness of such a hydroxylated surface would be approximately $0.2 \mathrm{~nm}$. In nanosized tricalcium silicate with an assumed particle radius of $44 \mathrm{~nm}$, consisting hypothetically of $43.8 \mathrm{~nm}$ unhydrated $\mathrm{Ca}_{3} \mathrm{SiO}_{5}$ and $0.2 \mathrm{~nm}$ hydroxylated surface, the volume fraction of the latter can be calculated to be $1 \%$. This implies that $1 \%$ of total silicon content is present in the hydroxylated surface layer if existing. In the samples from the paste experiment (water/solid-ratio $=1.20$ ), the fraction of silicon present as hydrated monomers is $79 \%$. This is much higher than the value assumed for a hydroxylated surface. It can be estimated from the NMR data that in the paste experiment a core of unhydrated tricalcium silicate (radius of $26 \mathrm{~nm}$ ) has remained which is surrounded by a rim of hydrated material that is $18 \mathrm{~nm}$ thick. Of course, the simplifications used in these calculations imply that the values only serve as a rough estimation. Nevertheless, there is clear evidence that it is not possible to attribute the whole amount of hydrated monomers to a hydroxylated surface or the presence of nano-cracks. Thus, a separate phase has to be considered instead. The estimated thickness of $18 \mathrm{~nm}$ for the intermediate phase is of the same order of magnitude as previously estimated by Rodger et al. ( $40 \mathrm{~nm}$ in [6]) and Livingston et al. (2-10 nm in [9]) for tricalcium silicate with a higher particle size. Gallucci et al. observed a C-S-H layer a few tens nm thick around cement particles after a few hours hydration by high-resolution electron microscopy [31]. It can be 
argued that the $\mathrm{Q}^{0}$ sites detected in this study may be present in the nuclei of $\mathrm{C}-\mathrm{S}-\mathrm{H}$ containing only uncondensed silicate at this time, but this argument can be ruled out by considering the high binding energies. It is not possible that holes are left in the structure of the nuclei that can be later filled with silicate ions.

The chemical composition of the intermediate phase can be estimated from the results of the chemical analysis of the sample from the paste experiment. The results were corrected due to the presence of calcium carbonate (measured by DSC/TG) and unhydrated tricalcium silicate (determined by NMR). A calcium/silicon-ratio of approximately 2.5 for the intermediate phase can be estimated by this approach which is similar to the ratio in the crystalline calcium silicate hydrate calciochondrodite.

The aforementioned discussion has shown that a separate phase containing hydrated silicate monomers forms during reaction of tricalcium silicate with water. Despite only a minor amount of this phase is present in samples with a common particle size distribution, the introduction of an intermediate phase in the reaction scheme for tricalcium silicate has a serious impact on this reaction since the kinetic of $\mathrm{Ca}_{3} \mathrm{SiO}_{5}$ hydration is drastically changed. As discussed in the introduction, a direct transformation of tricalcium silicate into $\mathrm{C}-\mathrm{S}-\mathrm{H}$ would take place within a few minutes. Only the reduction of the global rate of reaction due to the formation of an intermediate phase forming a protective shell around anhydrous particles allows proper mixing, transport, and placing of products containing $\mathrm{Ca}_{3} \mathrm{SiO}_{5}$ such as Portland cement. In the remaining part of this section, the early hydration of tricalcium silicate is discussed with a special focus on the induction period.

A transformation of the intermediate phase (product B) into $\mathrm{C}-\mathrm{S}-\mathrm{H}$ proves that the hydrate containing silicate monomers is metastable with respect to $\mathrm{C}-\mathrm{S}-\mathrm{H}$ under the conditions applied here $\left(21^{\circ} \mathrm{C}, 50 \%\right.$ calcium hydroxide solution). The hydrate containing monomeric silicate has a solubility lower than tricalcium silicate because it is formed from this phase. Furthermore, the intermediate phase has a solubility higher than $\mathrm{C}-\mathrm{S}-\mathrm{H}$ because it is transformed into $\mathrm{C}-\mathrm{S}-\mathrm{H}$ with time. The solubility curve of the intermediate phase lies between the solubility curves of the starting phase (tricalcium silicate) and the stable product $(\mathrm{C}-\mathrm{S}-\mathrm{H})$. Thus, an important condition is fulfilled for a reaction that proceeds in two steps through an intermediate phase [12]. Further evidence for this mechanism is the detection of a $\mathrm{Q}^{0}$ resonance by ${ }^{29} \mathrm{Si}\left\{{ }^{1} \mathrm{H}\right\} \mathrm{CP} / \mathrm{MAS}$ NMR spectroscopy over the whole course of the reaction [6].

Additionally, we have calculated if condensation of silicate tetrahedra may take place in solution, using the thermodynamic data by Felmy et al. [26]. At the low silicon concentrations measured during hydration of tricalcium silicate $(<100 \mu \mathrm{mol} / \mathrm{l})$, a fraction higher than $99.9 \%$ of silicon is present in solution as monomers. Condensation of the silicate units can only take place during precipitation.

It has been discussed in Section 1 that the direct reaction of tricalcium silicate with water to form $\mathrm{C}-\mathrm{S}-\mathrm{H}$ and calcium hydroxide should proceed very fast according to thermodynamic and kinetic calculations. This is in contradiction with the experimental observations. The experimental results display the presence of an induction period during the reaction of tricalcium silicate with water and a rate of reaction that is much smaller than expected for a direct reaction. However, the introduction of an intermediate phase allows an exact description of the experimental results by thermodynamic and kinetic calculations if it is assumed that the intermediate phase forms a protective shell around anhydrous particles. Such calculations have been performed and an outline is sketched below.

The transformation of the intermediate phase (product B) into $\mathrm{C}-\mathrm{S}-\mathrm{H}$ proceeds by a dissolution-precipitation process. In such reactions, the solubility of the starting solid is higher than the solubility of the final product. The dissolving phase is interested to establish an equilibrium with the solution. This leads to a supersaturation with respect to the final product. This is an important but not the only precondition that has to be fulfilled for the reaction to proceed. Also the presence of seeds or nuclei is an important factor. Three cases may be distinguished according to the classical theory of crystallization:

- In the presence of seeds of the final product, growth of these seeds can immediately take place even at the slightest supersaturation.

- In the absence of seeds, a homogeneous nucleation in the pore solution requires a rather high supersaturation. After formation of these nuclei, they are able to grow at modest supersaturation as in case 1.

- If no seeds are present and if the supersaturation in solution is not high enough to allow homogeneous nucleation, the nuclei may be formed on the surface of other materials by heterogeneous nucleation. Heterogeneous nucleation can also be preferred to homogeneous nucleation due to kinetic aspects. A low contact angle (high affinity) of the foreign substances to the nuclei is required for heterogeneous nucleation.

Heterogeneous and homogeneous nucleation may take place spontaneously if the supersaturation is high enough. At lower supersaturation, an induction period can be observed. The length of this period $t_{\text {ind }}$ mainly depends on the degree of supersaturation $\beta$ and a kinetic constant $K_{0}$ (Eq. (2)). Eq. (2) is based on earlier work of Nielsen and Söhnel [24] who investigated the kinetics of homogeneous nucleation of inorganic salts in aqueous solutions. This model holds for homogeneous and heterogeneous nucleation. The equation has been successfully used by Garrault-Gauffinet and Nonat [25] to derive data for the crystal-solution interfacial energy and $K_{0}$ for homogeneous nucleation of $\mathrm{C}-\mathrm{S}-\mathrm{H}$ and heterogeneous nucleation on calcite and dicalcium silicate. In order to simplify the discussion, we have replaced a term considering temperature $(T=298 \mathrm{~K})$, crystal shape factor $(f=16)$, solid-liquid interfacial energy $\left(\gamma=12 \mathrm{~mJ} / \mathrm{m}^{2}\right)$, and molar volume $\left(\Omega=0.25 \mathrm{~nm}^{3}\right)$ [25] by a constant factor $(F)$ in Eq. (2). The length of the induction period can be calculated using these values in combination with the supersaturation for $\mathrm{C}-\mathrm{S}-\mathrm{H}$ during hydration of tricalcium silicate.

$\ln t_{\text {ind }}=\frac{F}{\ln ^{2} \beta}-\ln K_{0}$

The supersaturation $(\beta)$ with respect to $\mathrm{C}-\mathrm{S}-\mathrm{H}$ is the ratio between the ion-activity product (IAP) and the solubility constant $\left(K_{\mathrm{SP}}\right)$ :

$\beta=\mathrm{IAP} / \mathrm{K}_{\mathrm{SP}}$

The supersaturation with respect to $\mathrm{C}-\mathrm{S}-\mathrm{H}$ depends on the solubility of the intermediate phase (curve $\mathrm{B}$ denoted by Jennings [12], kinetic path denoted by Barret $[2,10])$. It is not much higher than the solubility of $\mathrm{C}-\mathrm{S}-\mathrm{H}$ and not high enough to enable spontaneous nucleation. Thus, a true induction period is observed when the intermediate phase on the surface of tricalcium silicate reacts with water to form $\mathrm{C}-\mathrm{S}-\mathrm{H}$. To address this issue, the length of the induction period under different conditions was compared to derive information on the mode by which $\mathrm{C}-\mathrm{S}-\mathrm{H}$ nucleates and grows. A value $\beta=3.0$ for the supersaturation with respect to $\mathrm{C}-\mathrm{S}-\mathrm{H}$ during the reaction of $\mathrm{Ca}_{3} \mathrm{SiO}_{5}$ with water is assumed. The results obtained by conductivity measurements in diluted suspensions [25] are compared to isothermal heat conduction calorimetry experiments performed in this study (Table 2). In the investigations by calorimetry, $20 \%$ of tricalcium silicate (specific surface area $=4265 \mathrm{~cm}^{2} / \mathrm{g}$ by BET) was replaced by calcite, calcium hydroxide, and dicalcium silicate allowing heterogeneous nucleation on the surface of these materials (Fig. 11). The length of the induction period is estimated by extrapolating the curve of the second maximum to zero. In the case of calcite and calcium hydroxide this is complicated by peak overlap of the initial part of hydration.

The data presented in Table 2 show close agreement between data reported in the literature and those measured in this study in all cases 
Table 2

Comparison of calculated and measured values for the length of the induction period for homogeneous and heterogeneous nucleation of $\mathrm{C}-\mathrm{S}-\mathrm{H}$ on different surfaces.

\begin{tabular}{lll}
\hline & $\begin{array}{l}\text { Data from } \\
\text { reference [25] }\end{array}$ & $\begin{array}{l}\text { Measured by heat conduction } \\
\text { calorimetry (Fig. 11) }\end{array}$ \\
\hline $\begin{array}{l}\text { Homogeneous nucleation } \\
\text { Heterogeneous nucleation } \\
\text { on } \mathrm{Ca}_{3} \mathrm{SiO}_{5}\end{array}$ & $\begin{array}{l}\text { No data } \\
\text { Heterogeneous nucleation } \\
\text { on } \mathrm{Ca}_{2} \mathrm{SiO}_{4}\end{array}$ & $\begin{array}{l}\text { Not available } \\
170 \pm 30 \mathrm{~min}\end{array}$ \\
$\begin{array}{c}\text { Heterogeneous nucleation } \\
\text { on calcite }\end{array}$ & $55 \mathrm{~min}$ & $132 \pm 30 \mathrm{~min}$ \\
$\begin{array}{c}\text { Heterogeneous nucleation } \\
\text { on } \mathrm{Ca}(\mathrm{OH})_{2}\end{array}$ & No data & $54 \pm 20 \mathrm{~min}$ \\
\hline
\end{tabular}

where both types of data are available. A very long induction period is obtained for homogeneous nucleation by extrapolation to $\beta=3.0$. However, it cannot be compared with experimental data because it is not possible to avoid the presence of unhydrated tricalcium silicate that would allow heterogeneous nucleation on tricalcium silicate or intermediate phase in paste experiments. The calculated value indicates that homogeneous nucleation of $\mathrm{C}-\mathrm{S}-\mathrm{H}$ during its formation from the intermediate phase is extremely unlikely. If the composition of the aqueous phase is controlled by the solubility of the intermediate phase, the formation of nuclei can only take place by heterogeneous nucleation on tricalcium silicate or other surfaces having a high affinity to $\mathrm{C}-\mathrm{S}-\mathrm{H}$. Such materials have been investigated in this study (Table 2). They allow acceleration of the reaction of tricalcium silicate with water by shortening the induction period. Heterogeneous nucleation of $\mathrm{C}-\mathrm{S}-\mathrm{H}$ on tricalcium silicate covered by product $\mathrm{B}$ takes place after approximately $3 \mathrm{~h}$. In the presence of dicalcium silicate, the induction period is reduced from approximately 3 to approximately $2 \mathrm{~h}$. This substance is part of most Portland cement clinkers in the form of belite, stabilized by foreign ions and by rapid cooling of the clinkers in the cement kiln. Further acceleration is possible by adding calcite (induction period approximately $1 \mathrm{~h}$ ) or calcium hydroxide (immediate start of nucleation). This behavior is especially relevant to increase the early strength of paste, mortar, and concrete made using Portland cement. By adding the aforementioned substances, acceleration is possible by reducing the length of the induction period. The composition of the pore solution remains unaffected. A manipulation of the latter is able to increase the rate of reaction even further by changing the slope of the ascending part of the curve observed by isothermal heat conduction calorimetry [1]. Also the amount of nuclei formed at the end of the induction period has an important effect on the rate of reaction [27]. The addition of

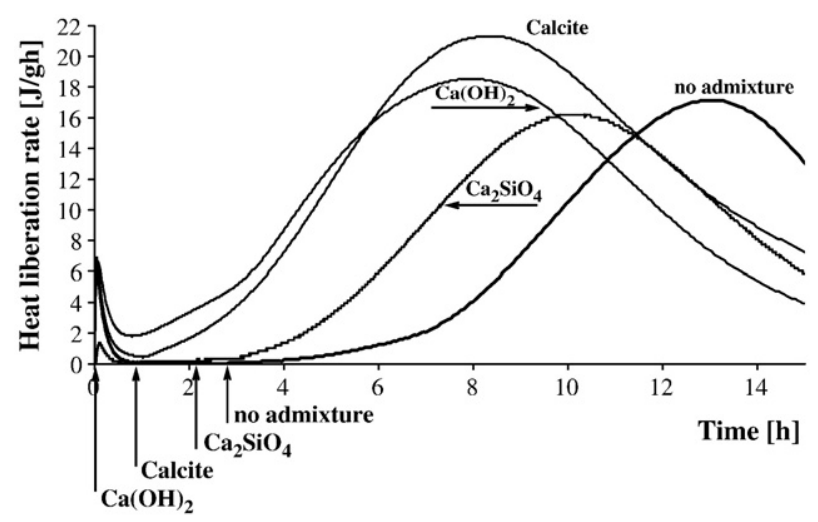

Fig. 11. Heat evolution during hydration of pure $\mathrm{Ca}_{3} \mathrm{SiO}_{5}$ (specific surface area $=4265 \mathrm{~cm}^{2} / \mathrm{g}$ ) and after replacement of $20 \% \mathrm{Ca}_{3} \mathrm{SiO}_{5}$ by other inorganic substances allowing heterogeneous nucleation $(w / s=0.50)$. seeds is rather complicated, but has been performed under specific conditions $[28,35]$.

\section{Conclusions}

The early hydration of laboratory made tricalcium silicate has been addressed in this study. A material with a very high specific surface area has been produced in order to increase the fraction of the early hydration product relative to the particle core of anhydrous $\mathrm{Ca}_{3} \mathrm{SiO}_{5}$. As a result of this high surface area, the starting material attracted a small amount of isopropanol (used in the grinding process) and water before initiation of the hydration experiments. The presence of these impurities has been considered in the derivation of the following conclusions:

- The use of $\mathrm{Ca}_{3} \mathrm{SiO}_{5}$ with a very low particle size $(40-200 \mathrm{~nm})$ has allowed us to obtain improved experimental evidence for the existence of an intermediate phase (denoted product $\mathrm{B}$ in the literature) containing hydrated silicate monomers. It has been shown that a sample hydrated for $5 \mathrm{~min}$ at a water/solid-ratio $=$ 1.20 contained $21 \%$ unhydrated tricalcium silicate and $79 \%$ product B. The latter cannot be attributed to the formation of a hydroxylated surface as previously proposed in the literature.

- A calcium/silicon-ratio of 2.5 has been estimated for the intermediate phase using chemical analysis, thermal analysis, and NMR data which is similar to the calcium/silicon-ratio for the crystalline calcium silicate hydrate calciochondrodite.

- Suspension experiments have been successfully used in earlier studies to derive important details regarding the hydration of tricalcium silicate. A significant difference observed in our study was the formation of nuclei of $\mathrm{C}-\mathrm{S}-\mathrm{H}$ in the suspension experiment (water/solidratio $=4000$ ) which contrasts results obtained in the paste experiment. The presence of these nuclei is able to accelerate the hydration in a way not commonly observed under paste conditions.

- Despite the amount of the intermediate phase (product $\mathrm{B}$ ) is very low at larger particle sizes, this phase controls the reaction of $\mathrm{Ca}_{3} \mathrm{SiO}_{5}$ with water. The consideration of such a phase allows proper explanation of the induction period observed in this reaction.

- The formation of $\mathrm{C}-\mathrm{S}-\mathrm{H}$ from product B during hydration of tricalcium silicate under paste conditions proceeds by heterogeneous formation of nuclei on the surface of tricalcium silicate covered by intermediate phase. The supersaturation is not high enough for a spontaneous formation of these nuclei. Instead of spontaneous nucleation, an induction period of approximately $3 \mathrm{~h}$ is observed. The length of the induction period can be reduced by heterogeneous nucleation on surfaces having a high affinity to these nuclei. Such substances discussed in this study are dicalcium silicate, calcite, and calcium hydroxide. The length of the induction period can be reduced from approximately $3 \mathrm{~h}$ to a few minutes by the addition of these substances.

- The present discussion is not complete and further studies need to consider additional details, such as growth of the surface layer consisting of product $B$ during the induction period [6]. Data presented in Table 2 and Fig. 11 refers to the same material with identical properties. A modification of properties such as different amount of crystallographic defect sites induced by a different thermal history $[29,30]$ is likely to add variations that are not considered in the current model.

This study complements the conclusions drawn from a careful analysis of available experimental data [1] and computer modeling [32] by directly synthesizing an intermediate phase that has been postulated before. A high solubility of the starting material in combination with a high dissolution rate allows the formation of amorphous precursors prior to the formation of the stable product thus obeying Ostwald's rule of stages. Similar processes have recently been discussed for many other reactions in organic and inorganic chemistry [33] such as the precipitation of calcium carbonate from solution [34]. 


\section{Appendix A. Estimation of the theoretical solubility of tricalcium silicate from thermophysical data}

\section{Table A1}

Thermodynamic data from V.I Babuskin, G.M. Matveev, O.P. Mcedlov-Petrosjan, Termodinamika silikatov, Strojizdat, Moscow, 1986. The data refer to standard conditions (pure phases, $25^{\circ} \mathrm{C}, 101.33 \mathrm{kPa}$, ideal behavior, concentration $1.0 \mathrm{~mol} / \mathrm{kg}$ ).

\begin{tabular}{lc}
\hline Compound & $\Delta_{\mathrm{f}} \mathrm{G}^{\circ}[\mathrm{kJ} /(\mathrm{mol} \cdot \mathrm{K})]$ \\
\hline $\mathrm{Ca}_{3} \mathrm{SiO}_{5}$ (crystalline) & -2784.3 \\
$\mathrm{H}_{2} \mathrm{O}$ (liquid) & -237.2 \\
$\mathrm{Ca}^{2+}$ (ion) & -552.7 \\
$\mathrm{H}_{2} \mathrm{SiO}_{2}^{2-}$ (ion) & -1186.1 \\
$\mathrm{OH}^{-}$(ion) & -157.3 \\
\hline
\end{tabular}

An assumption has to be made with respect to the deprotonation of the (monomeric) silicate ion. Since the hydroxide concentration is very high, $\mathrm{H}_{2} \mathrm{SiO}_{4}^{2-}$ was selected.

$\mathrm{Ca}_{3} \mathrm{SiO}_{5}+3 \mathrm{H}_{2} \mathrm{O} \rightarrow 3 \mathrm{Ca}^{2+}+\mathrm{H}_{2} \mathrm{SiO}_{4}^{2-}+4 \mathrm{OH}^{-}$

The change in Gibbs free energy for this reaction can be calculated:

$\Delta_{\mathrm{r}} \mathrm{G}^{\circ}=+22.5 \mathrm{~kJ} / \mathrm{mol}$

Using appropriate values for the gas constant $R$ and absolute temperature $T$, the following equation can be used to calculate the hypothetical solubility product:

$\Delta_{\mathrm{r}} \mathrm{G}^{\circ}=-R \cdot \mathrm{T} \cdot \ln 10 \cdot \log \mathrm{K}_{\mathrm{SP}}$.

It results in a hypothetical solubility product of

$\mathrm{K}_{\mathrm{SP}}=1.14 \cdot 10^{-4}$

with

$\mathrm{K}_{\mathrm{SP}}=\left\{\mathrm{Ca}^{2+}\right\}^{3} \cdot\left\{\mathrm{H}_{2} \mathrm{SiO}_{4}^{2-}\right\} \cdot\left\{\mathrm{OH}^{-}\right\}^{4}$.

Assuming congruent dissolution, the absence of other species and ideal behavior the equilibrium concentration is computed to

$\left[\mathrm{Ca}^{2+}\right]=0.319 \mathrm{~mol} / 1,\left[\mathrm{H}_{2} \mathrm{SiO}_{4}^{2-}\right]=0.106 \mathrm{~mol} / 1$, and $\left[\mathrm{OH}^{-}\right]=0.426 \mathrm{~mol} / 1$.

These values are much higher than found during hydration of tricalcium silicate. The exact computation is complicated by the fact that the calculation of activity coefficients is not straightforward at such high concentration. Nevertheless, it can be estimated that activity coefficients are lower than 1.0 and the ionic concentrations in a hypothetical aqueous solution that is equilibrium with tricalcium silicate are even higher than calculated above. It has to be kept in mind that at such high silicate and hydroxide concentrations, condensation and further deprotonation of silicate ions occur [26]. The presence of additional species increases the equilibrium concentration even further.

\section{References}

[1] H.F.W. Taylor, Cement Chemistry, Thomas-Telford, London, 1997.

[2] P. Barret, D. Bertrandie, Comment on Aqueous solubility relationships for two types of calcium silicate hydrate, J. Am. Ceram. Soc. 71 (2) (1988) C113-C115.

[3] H.N. Stein, Thermodynamic considerations on the hydration mechanisms of $\mathrm{Ca}_{3} \mathrm{SiO}_{5}$ and $\mathrm{Ca}_{3} \mathrm{Al}_{2} \mathrm{O}_{6}$, Cem. Concr. Res. 2 (2) (1972) 167-177.

[4] D. Damidot, F. Bellmann, B. Möser, T. Sowoidnich, Investigation of the early dissolution behaviour of $\mathrm{C}_{3} \mathrm{~S}, 12$ th International Congress on the Chemistry of Cement, Montreal, Canada, 2007, 8.-13.7., paper W1-06.5.
[5] L. Nicoleau, Interactions physico-chimiques entre le latex et les phases minérales constituent le ciment au cours de l' hydratation. PhD thesis, Université de Bourgogne, 2004

[6] S.A. Rodger, G.W. Groves, N.J. Clayden, C.M. Dobson, Hydration of tricalcium silicate followed by ${ }^{29}$ Si NMR with cross-polarization, J. Am. Ceram. Soc. 71 (2) (1988) 91-96.

[7] D. Ménétrier, I. Jawed, T.S. Sun, J. Skalny, ESCA and SEM studies on early $C_{3} S$ hydration, Cem. Concr. Res. 9 (4) (1979) 473-482.

[8] M. Regourd, J.H. Thomassin, P. Ballif, J.C. Tournay, Study of the early hydration of $\mathrm{Ca}_{3} \mathrm{SiO}_{5}$ by X-ray photoelectron spectroscopy, Cem. Concr. Res. 10 (2) (1980) 223-230.

[9] R.A. Livingston, J.S. Schweitzer, C. Rolfs, H.-W. Becker, S. Kubsky, Characterization of the induction period in tricalcium silicate hydration by nuclear resonance reaction analysis, J. Mater. Res. 16 (3) (2001) 687-693.

[10] P. Barret, D. Bertrandie, Fundamental hydration kinetic features of the major cement constituents: $\mathrm{Ca}_{3} \mathrm{SiO}_{5}$ and $\mathrm{BCa}_{2} \mathrm{SiO}_{4}$, J. Chim. Phys. $83(11 / 12)(1986)$ 765-775.

[11] M.W. Grutzeck, A.R. Ramachandran, An integration of tricalcium silicate hydration models in light of recent data, Cem. Concr. Res. 17 (1) (1987) 164-170.

[12] H.M. Jennings, Aqueous solubility relationships for two types of calcium silicate hydrate, J. Am. Ceram. Soc. 69 (8) (1986) 614-618.

[13] D. Damidot, A. Nonat, P. Barret, D. Bertrandie, H. Zanni, R. Rassem, $C_{3}$ S hydration in diluted and stirred suspensions: (III) NMR study of $\mathrm{C}-\mathrm{S}-\mathrm{H}$ precipitated during the two kinetic Steps, Adv. Cem. Res. 7 (1) (1995) 1-8.

[14] P. Barret, Evolution des idées sur l' hydratation de $C_{3} S$, Conference for the 100 years Anniversary of Lafarge's Research Center, Viviers, France, 1987, p. 25.

[15] J. Skibsted, L. Hjorth, H.J. Jakobsen, Quantification of thaumasite in cementitious materials by ${ }^{29} \mathrm{Si}\left\{{ }^{1} \mathrm{H}\right\}$ cross-polarization magic-angle spinning NMR spectroscopy, Adv. Cem. Res. 7 (1995) 69-83.

[16] H.P. Klug, L.E. Alexander, X-ray Diffraction Procedures for Polycrystalline and Amorphous Materials, John Wiley \& sons, New York, 1974, pp. 618-708.

[17] H.F.W. Taylor, A.B. Turner, Reactions of tricalcium silicate paste with organic liquids, Cem. Concr. Res. 17 (4) (1987) 613-623.

[18] N.I. Golovastikov, R.G. Matveeva, N.V. Belov, Crystal structure of the tricalcium silicate $3 \mathrm{CaO} \cdot \mathrm{SiO}_{2}=\mathrm{C}_{3} \mathrm{~S}$, Soviet Phys. Cryst. 20 (1976) 441-445.

[19] J. Skibsted, J. Hjorth, H.J. Jakobsen, Correlation between ${ }^{29} \mathrm{Si}$ NMR chemical shifts and mean Si-O bond lengths for calcium silicates, Chem. Phys. Lett. 172 (1990) 279-283.

20] A.-R. Grimmer, H. Zanni, ${ }^{29}$ Si NMR study of chemical shift tensor anisotropy of tricalcium silicate, in: P. Colombet, A.-R. Grimmer, H. Zanni, P. Sozzani (Eds.) Nuclear Magnetic Resonance Spectroscopy of Cement-Based Materials, Springer, 1998, pp. 57-68.

[21] J.F. Stebbins, Nuclear magnetic resonance spectroscopy of silicates and oxides in geochemistry and geophysics, in: T.J. Ahrens (Ed.), Handbook of Physical Constants, American Geophysical Union, Washington D.C, 1995, pp. 303-332.

[22] X. Cong, R.J. Kirkpatrick, ${ }^{29} \mathrm{Si}$ and ${ }^{17} \mathrm{O}$ NMR investigation of the structure of some crystalline calcium silicate hydrates, Adv. Cem. Bas. Mat. 3 (3-4) (1996) 133-143.

[23] M.R. Hansen, H.J. Jakobsen, J. Skibsted, ${ }^{29} \mathrm{Si}$ Chemical shift anisotropies in calcium silicates from high-field ${ }^{29}$ Si MAS NMR spectroscopy, Inorg. Chem. 42 (7) (2003) 2368-2377.

[24] A.E. Nielsen, O. Söhnel, Interfacial tensions electrolyte crystal-aqueous solution, from nucleation data, J. Cryst. Growth 11 (3) (1971) 233-242.

[25] S. Garrault-Gauffinet, A. Nonat, Experimental investigation of calcium silicate hydrate (C-S-H) nucleation, J. Cryst. Growth 200 (3-4) (1999) 565-574.

[26] A.R. Felmy, H. Cho, J.R. Rustad, M.J. Mason, An aqueous thermodynamic model for polymerized silica species to high ionic strength, J. Sol. Chem. 30 (6) (2001) 509-525.

[27] S. Garrault, A. Nonat, Hydrated layer formation on tricalcium and dicalcium silicate surfaces: experimental study and numerical simulation, Langmuir 17 (26) (2001) 8131-8138.

[28] D. Damidot, D. Sorrentino, D. Guinot, Factors influencing the nucleation and growth of the hydrates in cementitious systems: an experimental approach, 2nd International RILEM Symposium on Hydration and Setting, Dijon, France, 1997, pp. 161-197, 11.-13.6.

[29] P. Fierens, J.P. Verhaegen, Induction period of hydration of tricalcium silicate, Cem. Concr. Res. 6 (2) (1976) 287-292.

[30] P. Juilland, E. Gallucci, R.J. Flatt, K.L. Scrivener, Mechanisms of Hydration of Cementitious Materials at Early Age, 17, Internationale Baustofftagung-ibausil, Weimar, Germany, 2009, pp. 201-206, 23.-26.9.

[31] E. Gallucci, P. Mathur, K.L. Scrivener, Microstructural development of early age hydration shells around cement particles, Cem. Concr. Res. 40 (1) (2010) 4-13.

[32] J.W. Bullard, A determination of hydration mechanisms for tricalcium silicate using a kinetic cellular automaton model, J. Am. Ceram. Soc. 91 (7) (2008) 2088-2097.

[33] H. Coelfen, M. Antonietti, Mesocrystals and Nonclassical Crystallization, Wiley, Chichester, 2008.

[34] D. Gebauer, A. Völkel, H. Coelfen, Stable prenucleation calcium carbonate clusters, Science 322 (2008) 1819-1822.

[35] J.J. Thomas, H.M. Jennings, J.J. Chen, Influence of nucleation seeding on the hydration mechanisms of tricalcium silicate and cement, J. Phys. Chem. C. 113 (11) (2009) 4327-4334. 